\title{
Kano Model Analysis Required in APP Interactive Design based on Mobile User Experience
}

\author{
Xiaofei $\mathrm{Li}^{1}$ and Yue You ${ }^{2}$ \\ ${ }^{1}$ Beijing Information \& Science Technology University \\ ${ }^{2}$ Beijing Information \& Science Technology University \\ ustblxf2007@126.com; youyue1992@126.com
}

\begin{abstract}
The user experience in APP interactive designdraws more and more attention in the $A P P$ market where the user population expands continuously and the competition becomes increasingly intense, butcurrent studies mostly focus on the user website experience. This paper is intended to classify and study user needs in APP interactive design based on Kano model and Better-Worse coeffictent and gain Kano twodimensional attribute classification of user needsin the design. In addition, jt carries out analysis on these needs based on the better-worse coefficient.

Keywords: APP; User Experience; Kano model, Lnteractive Design
\end{abstract}

\section{Introduction}

With the advancement ofintelligent cerminal techrology, the mobile Internet services are available everywhere. The intelligent APP especially mobile phone APP, which integrates computer and Internef yith mobile communication technology,practically changes people's thinking, work and life-in modern times. Throughout China's mobile Internet market in 2015, the mobile terminal users presented a weak growth and approached the saturation point in quantity; the demographic dividend decreased in mobile Internet marke, and the mobile intelligent terminal devices slowed down in scale; the APP market in a fierce compettion stepped into the zero-sum era1. The APP survival rate was only $1 \%$ in 2012. APP developers should have the future targets, namely, technical in provement for products, reconstruction of business model and optimization of user experience if they maintalned manufacturing competitiveness.

Based on above, it Very important for APP developers to deeply understand and analyze the user experience and needs in APP interactive design. However, there are rare studies on APP aser experience in the past in China, and the studies on user experience in network focused on the website satisfaction. From the user needs, this paper is intended to quantize userexperience data, expand the range of studies on the factors influencing user experier ce inAPP interactive design, and enrich theoretical contents of interactive design and use experience, so that the theoretical support is provided to the user experience for interactive design of APP products.

\section{Relevant Studies}

\subsection{User Experience, Website User Experience and APP User Experience}

Bill Gates summed two most important factors for successfulproduct as user's happiness and learning from mistakes, where the user is a biggest learning source, and the user experience is more important for such an interactive product as a terminal device. As a few studies on APP user experience were conducted currently, this paper will carry out literature review in user experience, website user experience and APP user experience. 
In the mid of the 1990s, the user experience (UE/UX) was known widely, and it was defined as the "people's cognitive impression and responses to the products, system or services to be used or expected to be used". The UE, including subjective and objective experiences, is of strong ambiguity or fuzziness. Owing to its ambiguity, the UE is measured just only by the empirical evaluation method. Tom Tullis and Bill Albert (2008) defined the Usability Metrics, which was used to establish the relation between users and products in effectiveness, efficiency and satisfaction dimensions. Its metrics model focused on work effectiveness, and operated within a limited metric range. With development of hardware technology, the human-computer interaction is applied in all fields of life, and the user experience indexes are available from usability engineering to extensive fields, such as aesthetic feeling4 and user self-worth reflection5. Joseph Kramer and Sunil Noronha (2000) thought an important way to gain good user experience is applying user-centered design (UCD), which pays attention to the value from target users and personalized services provided for users, that is, the evaluation on user experience follows the whole life cycle of a product.

The researchers narrowed the focus of the user experience studyto website with development of human-computer interaction techniques. From quality management, the website user experience is measured mainly by the two indexes: qualit of service (QoS) and quality of experience (QoE). The primary evaluation index for computer network business is QoS, that is a widely-used service measure standard. Its eyaluation indexes include network throughout rate, network delay and packet loss pate, which can be regarded as utility of network protocol9. These indexes are manly applied in computer science field, and involved in website technology, but rot used for measurement of subjective feelings in user experience. The quality of experience (QoE) refers to the computer network users' subjective pereeption degree to application or services8. It can be used for the users' subjective evaluation 'on the QoS, and integrated with the influencing factors at service, userandenvironment levels9. Due to a greater influence by users' subjective attitude, a great challenge (1s encountered for measuring and studying QoE. Impractical application, Kerry Rodden el al. (2010) summed the measure indexes for traditional website user experiende as PULSE. The PULSE is a website evaluation index based on commerce-and technology, including page view, uptime, latency, seven day active user and earning. But these indexes are not applicable, or they are related to user experience, (UE) directly. There ss a bigger correlation coefficient among them, and they are nor used to identify that higher index data are functional or affected by user experience in a website. Based on the problems in PUSLE, Google Incorporation proposed a userexperience-centered measure framework-HEART, including happiness, engagement, adoption, retention, and task success 10 . This supplementary framework, as a measuring categoy, can be adjusted based on website use without all dimensions11.

APP was maimly applied in send-receive information and gaining inquiry as thefunctional software of terminal devices at first. With user needs and technology development, it has such more functions as games and GPS services. Like websites, the studies on mobile Internet QoS in the early time focus on such technology indexes as information receiving and sending, packet loss rate and usable information architecture 12. Essentially, the primary APP user population is public consumers rather than computer engineers. In addition, as the Uses and Gratifications that lay stress on the users' subjective is recognized and spread constantly13, the influence of individual users was taken seriously in the studies on APP user experience. Chun-Hua Hsiao (2015) and Hong (2006) thought that practicability, entertainment, social contact, experience degree and living habit of APP exert an influence on user experience and on if they would like continuing to apply APP14, 15. Wenhong Chen et al. (2008) demonstrated by empirical studies that the individual factors such as social and economic status and maturity can influence the application of mobile Internet16. RunhuaXu et al. (2016) confirmed by a large scale of empirical studies thatpersonality traits couldaffectpeople to select and use 
mobile phone APP, so the users' character and living habits were inferred based on the installed APP17. Different from user website experience, Dan J. Kim and Yujong Hwang (2010) held that the mobile terminal APP was difficult to gain users' trust due to its broadband restrictions, poor stability in connection, and unguaranteed safety. In addition, such disadvantages as small APP-carrying screen, low resolution and inconvenient and unfriendly function key incur bigger challenge to APP user experience. In their study, they classified APP applications into functional and entertainment applications, and explored the relation of network and design with content quality and APP user experience18. In China, many literatures about APP studies focused on the school-related mobile class or mobile library APP. The studies on APP in the core journal literature that were searched by the keyword "APP" on China National Knowledge Infrastructure (CNKI) Net were mostly involved in the mobile libraries in colleges and universities. Juilong Hung andKe Zhang (2011) analyzed the mobile learning trend during 2003-2008 using text mining technology 19 . Wen-Hsiung Wu (2012) reviewed the development tendency of mobile learning by Meta analysis20. The advancement of data anstysis and machine learning technology could overcome the restraints errors and toomuch work load in questionnaire survey, which was more convenient for the followng studies on APP users. For example, T. Kucukyilmaz et al. (2006) predieted people s gender by chatting records21, D. Nguyen et al. (2011) predicted users) age by linear regression using user blogs and forum texts22, and G. Chittaranjan et al. (2013) extracted the users' behavior features and personality traits by smartphone data 23 .

\subsection{Kano Model and its Applications in Relevant Fields}

(1) Kano model

It is not a linear relation between usersatisfaction products and product quality and services. Some qualities of a product may satis the users' minimum requirement, and others can provide the added valles 24 . The previous studies on product quality focused on three quality factors, namely, base, perfornance and excitement. Anderson, V(2000), K. Matzler and E. Sauerwein (2002) added the two factors, namely, indifferent and inverse quality factors related to castomer demands, to the study on user satisfaction 25,26 . Above five quality factors constitute the five quality elements of Kano model. The relation of product quality and user satisfaction is resolved with the distinguishing of product quality in Kano model. Kano model is also called the twodimension model. The two-dimensional model is an expanded one on the basis of the onedimensional one. The tro dimensions include: (a) The satisfactory degree measured from customers' subjectiye viewpoint; (b) The objective quality of products or services. The five quality elements $n$ Kano model are: attractive, must-be, one-dimensional, indifferent and reverse qualities 27 . Their functions are available as follows:

A. Attractive quality: refer to the quality which brings about surprises to users. It can't cause users dislike when it is not satisfied, but it can increase user satisfaction greatly.

B. Must be quality: refer to the quality that a product should have certainly. The product is up to standard only whenthe quality is satisfied, but the fully-dissatisfied quality can cause users' dislike.

C. One-dimensional quality: also called expected quality, and presenting a linear relation with user satisfaction. It is a quality feature of most intense competition among enterprises.

D. Indifferent quality: refer to the quality that the users don't care about. This quality doesn't affect user experience whether it is satisfied or not.

E. Reverse quality: The users are not satisfied if a product has this quality element.

Figure 1 shows the relation of user needs ( $\mathrm{X}$ axis) and user satisfaction ( $\mathrm{Y}$ axis) of five qualities. 


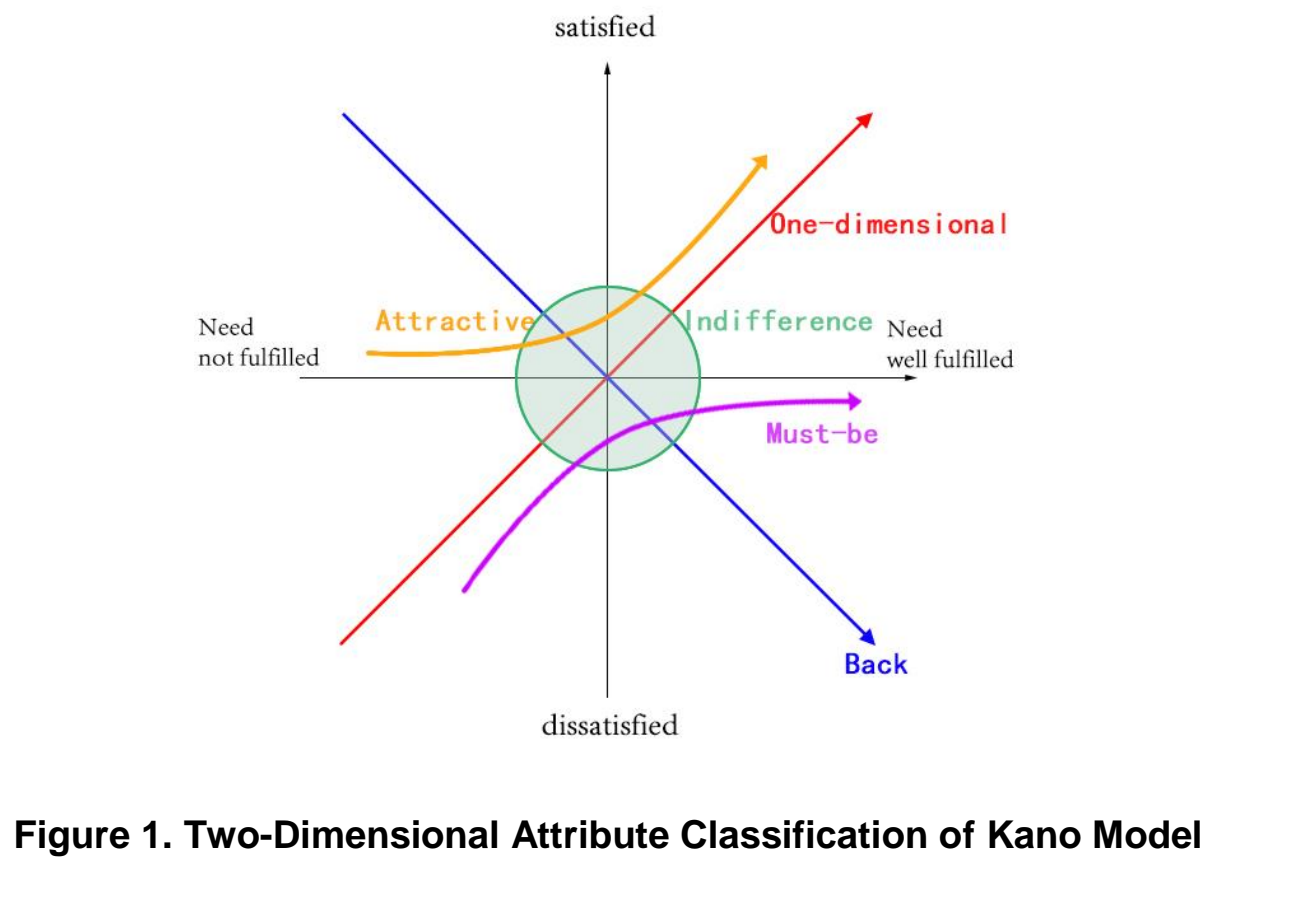

Kano model can be used to change the fuzzy qualities required by users into the visible quality elements, and classify them into the ones which can be displayed. Kano model is applied widely in division of product quality dimensions, so that consumers' demands for product attributes can be understood to improve product design and develop new products The studies in recent years have beef expanded in a multi-dimensional way to meet the analysis requirements in different eircumstances. Some scholars applied Kano model by combining qualitative and quantitative approach attributes. Charles Berger (1993) thoughtthat the Kano approach was a rudimental enlightenment in gaining and classification of customer satisfaction, and the skills and experience were needed for wellapplied Kano model. He introduced some skills and experience in his literatures2. Matzler and Hinte Rhuber et al. (1998) proposed an integration approach for Kano model and QFD (MH approach for short)28 Henk Jan Wassenaar et al. (2003) held that Kano model was a quantitative evaluation approach where the generalized form of customer utility function should be added to improve the prediction ability of discrete choice analysis. By this way, the user needs can be analyzed more precisely29. Tang Zhongjun and Long Yuling (2012) proposed the individual requirements elicitation approach of Kano model combined with fuzzy clustering and entropy evaluation method in order to balance the contradiction between customer satisfaction and product dimensions in the large-scale customized production30. MengQingliang and He Lin (2013) put forth the quality attribute classification based on fuzzy Kano model and fuzzy theory31. In engineering design, Kano model could be analyzed based on such quantitative approaches as conjoint analysis32 (Green and DeSarbo, 1978) and stated choice method33 (Louviere et al., 2000). Some scholars carried out further classification and subdivision for Kano model. For example, Timko et al. (1993) brought the two-dimensional expression of Kano quality classification based on user satisfaction coefficient 34 , where negative numbers were added in Kano model. In other related studies, a comprehensive method was applied that production capacity was taken into account, and the natures of user needs were understood precisely by combining Kano model into QFD planning matrix; the improvement rate of each user attribute was adjusted by transformation function on the basis of Kano model35.

In this study, Kano model is analyzed by the truthful data to obtain user needs in APP interaction design from the perspective of user needs. By this, some references and 
suggestions can be provided for APP interactive design as well as the promotion of user experience for APP products.

\section{Functional requirement classification of APP interactive design based on Kano model}

\subsection{Acquisition and classification of APP interactive design requirements}

In recent years, the definition of user experience (UE) has been studied in many studies, but few studies were involved in its quantization, especially mobile devices. Jaehyun Park et al. (2011) put forth a viewpoint that most mobile device user experience elements were integrated as simple index quantitative models. This kind of models have passed the testing in a business tablet computer case study, and this model has three elements for user experience measurements of whole mobile device; the three elements were further divided into 18 sub-elements. The framework model in this study was used by product or service designers to measure user experience value in product deyelopment36 as shown in Table 1 .

Table 1. Definition of Hierarchical Dimension For $0 x$

\begin{tabular}{|c|c|c|c|}
\hline Element & & Sub-element & \\
\hline \multirow{7}{*}{ usability } & a1 & Simplicity & $\begin{array}{l}\text { Way a produc//service works is simple, plain, and } \\
\text { uncomplicated }\end{array}$ \\
\hline & a2 & Directness & $\begin{array}{l}\text { Degree of user's perception of directly controlling the user } \\
\text { interface of a product/service }\end{array}$ \\
\hline & a3 & Efficiency & $\begin{array}{l}\text { which a product/service enables a task successfully } \\
\text { asting time or energy }\end{array}$ \\
\hline & a4 & In & $\begin{array}{l}\text { Degree to which a product/service is instructive and gives all } \\
\text { the necessary information to the user in a proper manner }\end{array}$ \\
\hline & $\mathbf{a}$ & & $\begin{array}{l}\text { ce can accommodate changes } \\
\text { nd those first specified }\end{array}$ \\
\hline & & & $\begin{array}{l}\text { Time and effort required for the user to learn how to use a } \\
\text { product/service }\end{array}$ \\
\hline & a7 & & $\begin{array}{l}\text { Ability for the user to operate a product/service easily through } \\
\text { its entire lifecycle }\end{array}$ \\
\hline \multirow{6}{*}{ Affect } & & Color & $\begin{array}{l}\text { Degree to which the color used in a product/service is likable } \\
\text { or vivid }\end{array}$ \\
\hline & b2 & Delicacy & $\begin{array}{l}\text { Degree to which a product/service is elaborate, or finely and } \\
\text { skillfully made }\end{array}$ \\
\hline & b3 & Texture & $\begin{array}{l}\text { Degree to which a product's texture or touch appeals to the } \\
\text { users }\end{array}$ \\
\hline & b4 & Luxuriousness & $\begin{array}{l}\text { Degree to which a product/service is luxurious or looks } \\
\text { expensive and superior in quality }\end{array}$ \\
\hline & b5 & Attractiveness & $\begin{array}{l}\text { User's perception that a product/service is pleasing, arousing, } \\
\text { interesting, and attractive }\end{array}$ \\
\hline & b6 & Simplicity & $\begin{array}{l}\text { Way a product/service looks is simple, plain, and } \\
\text { uncomplicated }\end{array}$ \\
\hline User value & c1 & Self-satisfaction & $\begin{array}{l}\text { Degree to which a product/service gives a user satisfaction } \\
\text { with oneself or one's achievements }\end{array}$ \\
\hline
\end{tabular}




\begin{tabular}{|c|l|l|l|}
\hline & c2 & Pleasure & $\begin{array}{l}\text { User's feeling of being pleased or gratified due to interacting } \\
\text { with a product/service }\end{array}$ \\
\cline { 2 - 4 } & $\mathbf{c 3}$ & Customer need & $\begin{array}{l}\text { Degree to which functions or appearances of a product/service } \\
\text { satisfy the user's needs }\end{array}$ \\
\cline { 2 - 4 } & c4 & Sociability & $\begin{array}{l}\text { Degree to which a product/service satisfies the user's desire to } \\
\text { be sociable }\end{array}$ \\
\cline { 2 - 4 } & $\mathbf{c 5}$ & Attachment & $\begin{array}{l}\text { Ability for the user to attach subjective value to a } \\
\text { product/service }\end{array}$ \\
\hline $\begin{array}{c}\text { Overall } \\
\text { user } \\
\text { experience } \\
\text { (ux) }\end{array}$ & d1 & $\begin{array}{l}\text { Overall values of user's experience from interacting with a } \\
\text { product/service }\end{array}$ \\
\hline
\end{tabular}

In this paper, questionnaires are classified into three categories based on the classification in this study. This framework is improved and adjusted though the brainstorming discussion was made by APP product managers with many years of work experience and APP phone-using classmates. All elements that affect APP user experience are distinguished and sequenced carefully and effectively. At last, the user needs are investigated and surveyed in the mode of Kanomodel.

\subsection{Design, Distribution and Test}

(1) Questionnaire design

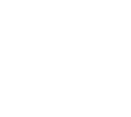

The questionnaire designed in this study Is made up of four parts: APP usability, users' sense experience to APP, value embodiment of APP users and users' basic information, where, the first two parts are the core of his stady, the data results in the third part are related to the first two parts to agreat extent, and the fourth part states collection of information on statistical features and phone Internet-surfing habits of survey respondents. The user attitudes in scenes of APP and non-APP functions are investigated in Kano questionnaires, presenting positive and reverse issues.

In order to ensure the purpose meanings of questionnaire are understood by the respondents, threetask are added in this survey:

a. Explanation and illustration of gbscure issues in questionnaires.

b. Explanations to choices of "Dislike" and "Live-with" in the questionnaire, so that respondents could complete the questionnaire in a uniform standard.

c. The pre-intervie was made to the three users who often used mobile phone APP, and they were Required to put forth their own questionable issues after completing questionnalres and check the questions set in questionnaire were understood or not. The discussion, improvement and supplementation should be made for the unapprehended questions.

(2) Distribution and testing of questionnaires

This survey was made in a way of network issuing questionnaires, and a professional questionnaire survey website-Questionnaire Star was employed. The survey lasted one week by the author's releasing and links in a social media network platform, inviting respondents for questionnaires and inter-filling in questionnaires. 220 questionnaires were collected totally. The invalid questionnaires were excluded by data cleansing, and finally total of 201 valid questionnaires were included in data analysis. Through SPSS analytical test, the Cronbach's Alpha coefficients with three dimensions of APP usability, APP sense experience and APP user value embodiment were: 0.910, 0.892 and 0.823 , which all were greater than 0.8 . These numbers were normal and their reliability coefficients were accepted. By factor analysis, $\mathrm{KMO}$ value was 0.950 , i.e. KMO value was greater than 0.7 , indicating the structure validity was good for the questionnaires. 


\section{Data Analysis}

\subsection{Basic Information of Respondents}

Through analysis and sort-out of valid questionnaire data, the respondents' demographic information in this survey is shown in Table 2.

Table 2. Respondents' Demographic Information

\begin{tabular}{|c|c|c|c|}
\hline Statistic item & Choice & Quantity & Percentage \\
\hline \multirow{2}{*}{ Gender } & Male & 88 & $43.78 \%$ \\
\hline & Female & 113 & $56.22 \%$ \\
\hline \multirow{6}{*}{ Age } & Below 18 years old & 2 & $1.00 \%$ \\
\hline & $18-25$ years old & 70 & $34.83 \%$ \\
\hline & $26-30$ years old & 82 & $40.80 \%$ \\
\hline & $31-40$ years old & 41 & $20.40 \%$ \\
\hline & $41-45$ years old & 4 & \\
\hline & Over 45 years old & 2 & $1.00 \%$ \\
\hline \multirow{4}{*}{$\begin{array}{l}\text { Education } \\
\text { background }\end{array}$} & Senior high school or below & 21 & $10.45 \%$ \\
\hline & Undergraduate (colleg & 155 & $77.11 \%$ \\
\hline & Postgraduate & 19 & $9.45 \%$ \\
\hline & Doctor or above & 6 & $2.99 \%$ \\
\hline \multirow{7}{*}{ Occupation } & Stadent & 75 & $37.31 \%$ \\
\hline & $\begin{array}{c}\text { adminstration bodies, state- } \\
\text { owned enterprises, and public } \\
\text { institations }\end{array}$ & 19 & $9.45 \%$ \\
\hline & Workers in föreign companies & 21 & $10.45 \%$ \\
\hline & Workers in private enterprises & 39 & $19.40 \%$ \\
\hline & Freelances & 36 & $17.91 \%$ \\
\hline & Others & 11 & $5.47 \%$ \\
\hline & First-tier cities & 51 & $25.37 \%$ \\
\hline \multirow{3}{*}{$\begin{array}{l}\text { Residential city } \\
\text { level }\end{array}$} & Second-tier cities & 82 & $40.80 \%$ \\
\hline & Third-tier cities & 48 & $23.88 \%$ \\
\hline & Over third-tier cities & 20 & $9.95 \%$ \\
\hline \multirow{9}{*}{$\begin{array}{l}\text { Mobile phone } \\
\text { system for use }\end{array}$} & Below 3000 YUAN & 49 & $24.38 \%$ \\
\hline & $3000-6000$ YUAN & 107 & $53.23 \%$ \\
\hline & $6000-10000$ YUAN & 40 & $19.90 \%$ \\
\hline & $10000-20000$ YUAN & 4 & $1.99 \%$ \\
\hline & Over 20000 YUAN & 1 & $0.50 \%$ \\
\hline & Apple iOS & 67 & $33.33 \%$ \\
\hline & Android & 129 & $64.18 \%$ \\
\hline & Windows Phone & 4 & $1.99 \%$ \\
\hline & Others & 1 & $0.50 \%$ \\
\hline \multirow{3}{*}{$\begin{array}{l}\text { Frequency for use } \\
\text { of mobile phone } \\
\text { APP }\end{array}$} & $>3$ hours per day on average & 103 & $51.24 \%$ \\
\hline & $>2$ hours per day on average & 63 & $31.34 \%$ \\
\hline & $>1$ hours per day on average & 23 & $11.44 \%$ \\
\hline
\end{tabular}




\begin{tabular}{|c|c|c|c|} 
& $>0.5$ hours per day on average & 7 & $3.48 \%$ \\
\cline { 2 - 4 } & $\begin{array}{c}\text { Using occasionally if } \\
\text { necessary }\end{array}$ & 5 & $2.49 \%$ \\
\hline \multirow{2}{*}{$\begin{array}{c}\text { Primary networking } \\
\text { ways for mobile } \\
\text { phones }\end{array}$} & Wi-Fi & 141 & $70.15 \%$ \\
\cline { 2 - 4 } & $4 \mathrm{G}$ & 54 & $26.87 \%$ \\
\cline { 2 - 4 } & $3 \mathrm{G}$ & 5 & $2.49 \%$ \\
\hline
\end{tabular}

Some features of respondents can be known from the table: (a) Females are more than males but in a less different; (b) Population: mostly college students at 18-30 years old, as well as workers working for not a long term in private enterprises, with limited incomes and general consumption level; (c) Education: undergraduates (college students), with higher frequency in use of mobile phone APP; (d) Primary networking way for use of mobile phone: Wi-Fi; Android mobile phone system is mainly used for mainstream users.

\subsection{Kano Two-Dimensional Classification Required by APP Interactive Design}

Each question is included into the model in Table 3 by pros and cons items. There is a score in attributes for gathering data for each question, and the sum of numerical values of the same attributes can be obtained through Kano model analysis. The attributes and the biggest one are the category of this functionar attribute. The elements set in questionnaires are classified by applying above analysis mode, and the gesults see Table 3.

Table 3, Kano Evaluation

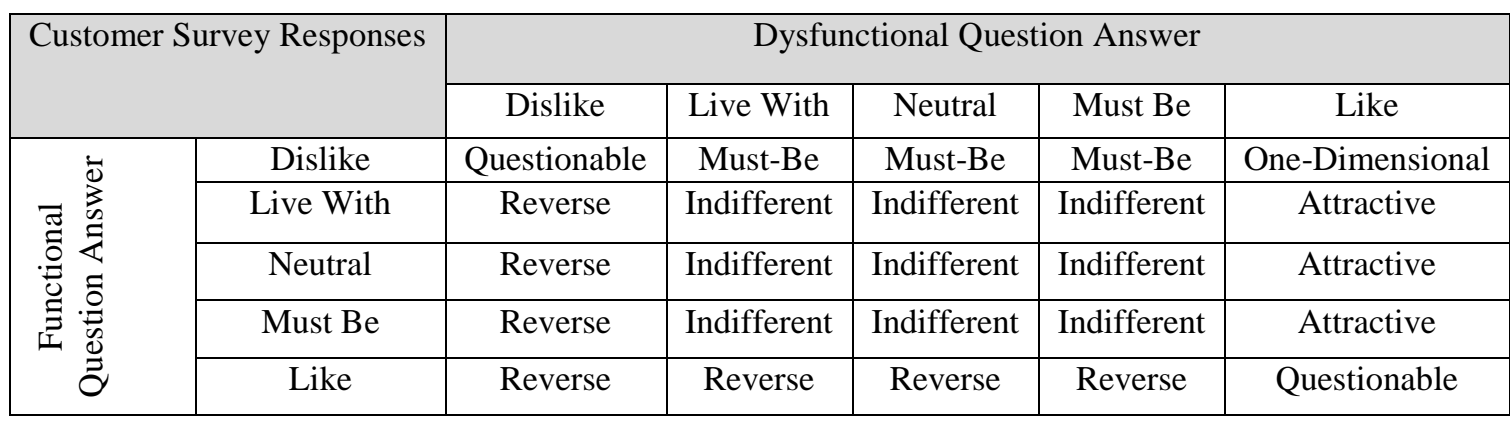

\subsection{Better-Worse coefficient analysis}

After Kaho attribute are classified, the Better-Worse coefficient can be worked out based on percentages calculated by Kano classification. If the Better value is generally positive we can know the satisfaction coefficient of the APP-owned element through Better value. The bigger the value is, the better the effect of the element to improve user satisfaction is. If the Worse value is generally negative, the user satisfaction can decrease when APP has no this element. The bigger the negative value is, the more the user satisfaction decreases. It is found through Better-Worse coefficient the increase or removal of one element can exert an influence on APP user experience. The index calculation formula ${ }^{3}$ proposed by Berger (1993) is stated as follows:

Like coefficient for (Better) after the element increases: (Attractive + Mustbe)/(Attractive + One-dimensional + Indifferent factor).

Dislike coefficient for (Worse) after the element is removed: (One-dimensional + Must-be $) /($ Attractive + One-dimensional + Must-be + Indifferent factor $) \times(-1)$. 
The calculation is done for Better-Worse coefficients of elements by above formula, and the results are listed in Table 4.

Table 4. Analysis Results of APP Interactive Design User Experience Factors

\begin{tabular}{|c|c|c|c|c|}
\hline $\begin{array}{c}\text { Kano } \\
\text { evaluation }\end{array}$ & Sub-element & Element & $\begin{array}{c}\text { Better- } \\
\text { worth }\end{array}$ & $\begin{array}{l}\text { Worse- } \\
\text { worth }\end{array}$ \\
\hline \multirow{3}{*}{ Must-Be } & Simple operation & \multirow{2}{*}{ Usability } & 0.3 & -0.51 \\
\hline & No ads & & 0.55 & -0.61 \\
\hline & Rational layout & Affect & 0.48 & -0.58 \\
\hline \multirow{6}{*}{$\begin{array}{c}\text { One- } \\
\text { Dimenslonal }\end{array}$} & Direct implementation of function & \multirow{4}{*}{ Usability } & 0.54 & -0.58 \\
\hline & Efficiency & & 0.56 & -0.51 \\
\hline & Easy to learn & & 0.56 & 0.51 \\
\hline & Data transmission is stable & & & -0.31 \\
\hline & Satisfactory after-sale service & & & -0.53 \\
\hline & Personal information security & & & -0.63 \\
\hline \multirow{4}{*}{ Attractive } & Rational information & & 0.58 & -0.44 \\
\hline & Occupy a small memory & & 0.59 & -0.51 \\
\hline & Minimalist design & Affect & 0.48 & -0.3 \\
\hline & Provide additional services & User value & 0.65 & -0.35 \\
\hline \multirow{10}{*}{ Indifferent } & Individualized customizable & \multirow{8}{*}{ Affect } & 0.39 & -0.14 \\
\hline & No forced user login & & 0.52 & -0.53 \\
\hline & Color harmony & & 0.48 & -0.38 \\
\hline & Elegant details & & 0.41 & -0.14 \\
\hline & Smooth switching interfac & & 0.41 & -0.13 \\
\hline & Gorgeous interface & & 0.36 & -0.11 \\
\hline & Ine esting interface & & 0.37 & -0.09 \\
\hline & & & 0.23 & -0.13 \\
\hline & & \multirow{2}{*}{ User value } & 0.38 & -0.19 \\
\hline & Meet the social needs & & 0.52 & -0.16 \\
\hline
\end{tabular}

\section{Conclusions and Prospects}

\subsection{Priority Ranking of Kano Attributes Require in APP Interactive Design}

The primary index concerned in this paper is Kano attribute classification in APP interactive design elements. According to the results, most of APP sense experience dimensions belong to indifferent attributes, and the users have too many needs for aesthetics in APP interface design.

One primary function for Kano model is the rank ordering of user needs in priority, and the order is: must-be, one-dimensional, attractive and indifferent. The results see Table 4.

\subsection{Application of Kano Model in APP Interactive Design}

In APP interactive design, the must-be attribute should be satisfied in the first place when APP user satisfaction decreases substantially without the element provided. In the three points, the Better-Worse coefficient is biggest for non-hard-sell ads in APP, but whether the hard-sell ads have the biggest influence on user satisfaction. In the second place, the one-dimensional attribute should be satisfied when APP user satisfaction 
deceases without the element provided. The four elements in one-dimensional attribute belong to APP usability, but whether APP is convenient and usable is an important basic element of user experience in interactive design. The Better-Worse coefficient is bigger for the element which has good APP safety, where there is no user information disclosed and plug-in installing risk. So this element should be concerned mainly in APP development. The elements in the must-be and one-dimensional attributes should be available for APP. Though the elements can't increase the value of user satisfaction, their decrease can cause an adverse effect on user satisfaction. Thus, they are developed and optimized in priority.

The attractive attribute can't exert an adverse effect on user experience in APP interactive design without attractive attribute existing. Otherwise, it can bring surprises to users. The elements with higher Better value should be developed in priority, so that "APP can provide added services to meet user needs in many aspects". For example, the running APP is added with the nearby running site recommended by users, and if the weather is suitable or not for outdoor exercise. In APP development, high attention should be paid to attractive attribute element. If APP provides reasonable information, with a small space in the memory simple and striking design, and value-added services provided, such attractive experience tool can offer users surprises and satisfaction though it can't affect main APP functions. So the APP will be the best of the same kind.

In results of this survey, most of elements are notessential for APP, and not too much effect of indifferent elements is exerted on users for whether these elements exist or not. These elements can be seen as the ones that are cost-effective in APP development. So, APP development companies don't exhaust too much energyand money in design, update and style customizing of APP interface as well as social contact functions. This may be affected less or more by most the usens in this survey who belong to the medium-low consumption class and mainly live in the secondtier cities. This is also likely because the APP design styles are largely identical but with minor differences at home currently, and they offer too many surprises and expectations to users in sense experience. So it is also reasonable that the styles can't satisfy the users active needs.

Because of the small ample size, the paper does not analyze the various satisfaction factors of different dennographic variables. In future research, the research will be carried out in large samples.

It is worth noting that Kano attribute classification changes with advancement of time and technology and the demands of users for APP interactive design change constantly. When basic APP usablit element techniques satisfy users' psychological standards thoroughly, APP sense experience can become the attractive attribute required in APP interactive design, and APP also will become a shining focus in APP market competition.

\section{Acknowledgements}

This paper has benefited from the comments and suggestions of editor and two anonymous reviewers.

\section{References}

[1] T. Tullis and B. Albert, "Measuring the User Experience: Collecting, Analyzing, and Presenting Usability Metrics", Morgan Kaufmann, American, (2008).

[2] N. Tractinsky, A. Katz and D. Ikar, "What is beautiful is usable", Interacting with Computers, vol. 2, no. 13, (2000)

[3] J. Kramer, S. Noronha and J. Vergo, "A user-centered design approach to personalization", Communications of the ACM, vol. 8, no. 43, (2000).

[4] C. Lin, Y. Li and J. Wan, "A review of optimization methods for the quality of computer network service", Chinese Journal of Computers, vol. 1, no. 34, (2011).

[5] M. Hassenzahl, "Human-Computer Interaction Series", Springer Netherlands, Kluwer, vol. 7, (2003), pp. 31-42. 
[6] ITU-T: Definition of quality of experience (QoE). International Telecommunication Union, Liaison Statement, Ref.: TD 109 rev 2(PLEN/12), (2007).

[7] M. Volk, J. Sterle and U. Sedlar, "An approach to modeling and control of QoE in next generation networks", IEEE Communications Magazine, vol. 8, no. 48, (2010).

[8] K. Rodden, "Hilary Hutchinson and Xin Fu, Measuring the User Experience on a Large Scale: UserCentered Metrics for Web Applications", Proceedings of CHI, ACM Press, (2010).

[9] H. Kim, J. Kim and Y. Lee, "An Empirical Study of Use Contexts in the Mobile Internet, Focusing on the Usability of Information Architecture", Information Systems Frontiers, vol. 2, no. 7, (2005).

[10] T. E. Ruggiero, "Uses and Gratifications, Theory in the 21 st Century", Mass Communication and Society, vol. 1, no. 3, (2000).

[11] C. H. Hsiao, J. J. Chang and K. Y. Tang, "Exploring the influential factors in continuance usage of mobile social Apps: Satisfaction, habit, and customer value perspectives", Telematics and Informatics, vol. 2 , no. 33, (2016).

[12] S. J. Hong, J. Y. L. Thong and K. Y. Tam, "Understanding continued information technology usage behavior: A comparison of three models in the context of mobile internet", Decision Support Systems, vol. 3 , no. 42, (2006).

[13] C. W. Boase and J. B. Wellman, "The internet in everyday life", Haythomthwaite, UK, (2008), pp.74 113.

[14] R. Xu, R. M. Frey, E. Fleisch and A. Ilic, "Understanding the impact of personality traits on mobite app adoption-Insights from a large-scale field study", Computers in Human Behavior, vol. 9, no 62, (2016).

[15] D. J. Kim and Y. Hwang, “A study of mobile internet user's service quality perceptions from a user's utilitarian and hedonic value tendency perspectives", Communications of the ACM, vol. 9, no. 14, (2010).

[16] J. L. Hung and K. Zhang, "Examining mobile learning trends 2003-2008. a categorical meta-trend analysis using text mining techniques", Journal of Computing in Higher Education, vol. 4, no. 24, (2012).

[17] W. H. Wua, Y. C. J. Wu, C. Y. Chen, H. Y. Kao, C. H. Lin and S. H. Huang, "Review of trends from mobile learning studies: A meta-analysis", Computers \& Education, vol, 2, no. 59, (2012).

[18] T. Kucukyilmaz, B. Cambazoglu, C. Aykanat and F. Can, "Chat mining for gender prediction", Advances in information system, vol. 10, no. 4243, (2006).

[19] D. Nguyen, N. Smith and C. Rosé, "Author age prediction from text using linear regression", Proceedings of the 5th ACL-HLT Workshop on Language, Technology for Cultural Heritage, Social Sciences, and Humanities, Stroudsb ro, PA, USA, (2011).

[20] G. Chittaranjan, J. Blom and D. G. Perez, "Mining large-scale smartphone data for personality studies", Personal and Ubiquitous Computing, vol. 3, no. 17, (2013).

[21] B. Fynes and S. De Búrca, "The effects of design quality on quality performance", International Journal of Production Economics (yol 1, no. 96, (2015).

[22] E. W. Anderson and Mittal, "Strengthening the satisfaction-profit chain", Journal of Service Research, vol. 2, no 3, (2000).

[23] K. Matzler and-E. Sauerwein, "The factor structure of customer satisfaction: An empirical test of the importance grid and the penalty-reward-contrast analysis", International Journal of Service Industry Management, vol. 4, no 13 (2000).

[24] N Kano, N Seraku, F Takahashi and S Tsuji, "Attractive Quality and Must-be Quality", Journal of Japanese Society for Quality Control (in Japanese), vol. 2, no. 14, (1984).

[25] Q. Xu, R. J. Jiao and X. Yang, "An Analytical Kano Model for Customer Needs Analysis", Design Studies, vol. 1, 10. 30, (2009).

[26] H. J. Wassendar, W. Chen, J. Cheng and A. Sudjianto, "Enhancing discrete choice demand modeling for decision-based design", ASME Journal of Mechanical Design, vol. 4, no. 127, (2005).

[27] J. Park, S. H. Han, H. K. Kim, S. Oh and H. Moon, "Modeling user experience: A case study on a mobile device", International Journal of Industrial Ergonomics, vol. 2, no. 43, (2013).

[28] 7. Tang and Y. Long, "Research on Method of Acquiring Individual Demand Based on Kano Model", Journal of Soft Science, vol. 2, no. 26, (2012).

[29] Q. Meng and L. He, "Fuzzy-KANO-Based Classification Method and its Application to Quality Attributes", Journal of Industrial Engineering, vol. 3, no. 16, (2013).

\section{Authors}

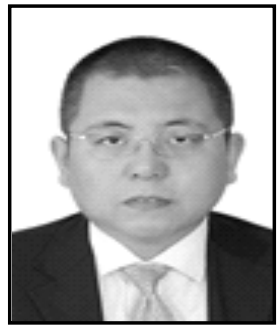

Xiaofei Li, Male, 38-years old, Vice Professor in the school of Economic and Management, Beijing Information Science \& Technology University, No.12 at the east road of Qinghe Xiaoying, Haidian District, Beijing, 100192, ustblxf2007@126.com, (86)13488787089 


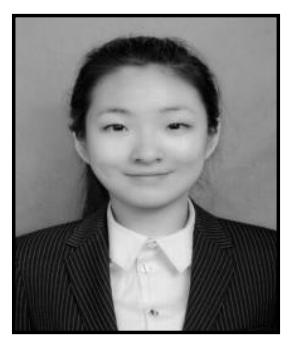

Yue You, Female, 24-years old, postgraduate of Industrial Engineering in the school of Economic and Management, Beijing Information Science \& Technology University, No.12 at the east road of Qinghe Xiaoying, Haidian District, Beijing, 100192, youyue1992@126.com, (86)13041181269.

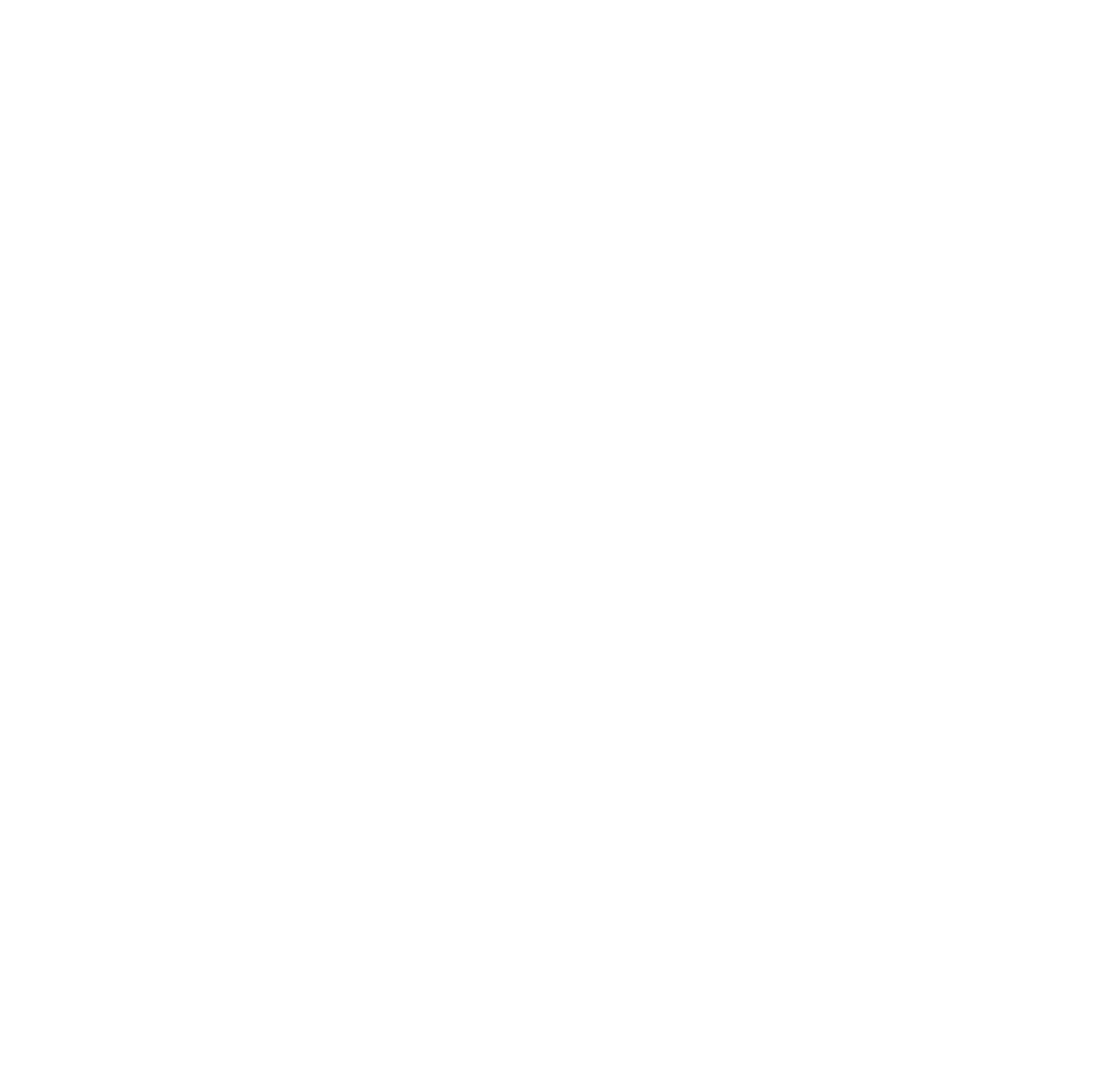

